\title{
Fuzzy Metagraph and Rule Based System for Decision Making in Share Market
}

\author{
Pankaj Dashore \\ Reader SOC\&E, IPS Academy \\ Indore (MP), INDIA
}

\author{
Dr.Suresh Jain \\ Professor \& HOD (CE), IET DAVV \\ Indore (MP), INDIA
}

\author{
Smt. Rachna Dashore \\ Lecturer \\ Indore, INDIA
}

\begin{abstract}
This paper explores the possibility of applying fuzzy logic theory for handling vagueness and imprecision that characterize the decision making process. Fuzzy metagraph framework is developed to carry out the required analysis for arriving at the governance rating of the firms. A person carrying a share of a company holds that part of ownership in that company Share is nothing but the Ownership of the company divided into small parts and each part is called as Share or Stock. Share market is the place where buying and selling of shares takes place, with the use of computer display datas on screen. A person holding maximum shares carry maximum ownership and designated like director, chairman etc. This research work will help the customer for decision making in share market.
\end{abstract}

\section{Keywords}

Market growth, share price, fuzzy logic.

\section{INTRODUCTION}

Stock market is an important pillar of each economy. Share is the Ownership of the company divided into small parts and each part is called as Share or Stock. A stock exchange is a corporation or mutual organization which provides "trading" facilities for stock brokers and traders, to trade stocks and other securities. A trader who is looking to profit from the market has to have faith on the company where he is putting his money. Technical analysis uses price and other similar daily input data, and the fundamental analysts use fundamental data which are normally published on an annual basis or quarterly. Technical and fundamental approaches are used in parallel to estimate short-term and longterm return and risk.

This paper explores the possibility of applying fuzzy logic theory for handling vagueness and imprecision that characterize the decision making process. Fuzzy Logic framework is developed to carry out the required analysis for arriving at the governance rating of the firms. This research work will help the customer for decision making in share market A person carrying a share of a company holds that part of ownership in that company Share is nothing but the Ownership of the company divided into small parts and each part is called as Share or Stock. Share market is the place where buying and selling of shares takes place. The buying and selling of shares takes place from anywhere, wherever with the help of internet connected computer. One should need the demat account, computer and internet connection and he/she can start the share trading or investing. When you place the buy order in India, the message is transferred to the exchange [either NSE \{National Stock Exchange or BSE \{Bombay Stock Exchange\}] and the order stays in the queue of exchange's other orders and gets executed if the price of that share comes to that value. Once you get the confirmation of this transaction, the shares purchased, will be sent to your demat account. The shares will be stored in demat account in electronic format. The Sensex is an "index". An index is basically an indicator. It gives you a general idea about whether most of the stocks have gone up or most of the stocks have gone down. In India the Sensex is an indicator of all the major companies of the BSE and the Nifty is an indicator of all the major companies of the NSE. If the Sensex goes up, it means that the prices of the stocks of most of the major companies on the BSE have gone up. If the Sensex goes down, this tells you that the stock price of most of the major stocks on the BSE have gone-down. The Sensex represents the top stocks of the BSE and the Nifty represents the top stocks of the NSE. Besides Sensex and the Nifty there are many other indexes Many different types of investors hold the shares of a company.

The share market position graph NSE graph BSE graph are shown below.

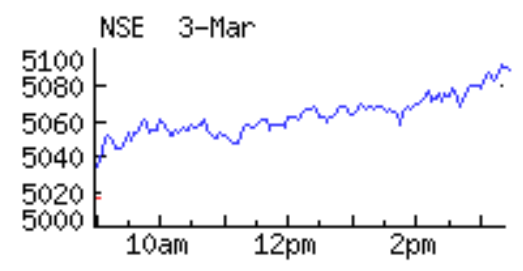

Fig(a)

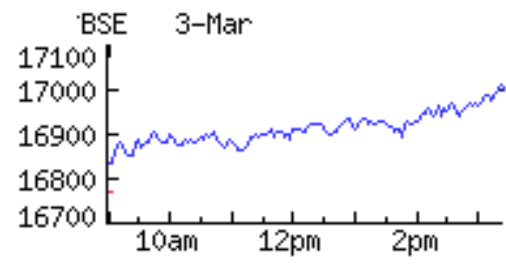

$\operatorname{Fig}(\mathbf{b})$

Fig.1: Stock market graph for 3 march 2010 (a) NSE graph (b) BSE graph .

\section{FUZZY CONTROLLER}

Fig.2 gives the structure of a fuzzy controller, which is essentially the structure of a Mamdani technical fuzzy controller. Trend in prices information is the Crisp input which is fuzzyficated to mapped on fuzzy sets. We evaluate stock price 
and the trend in prices over some period of time and then decide whether to trade based on simple rules. The result is in each case a real number in the interval $\left[\begin{array}{ll}0 & 1\end{array}\right]$.

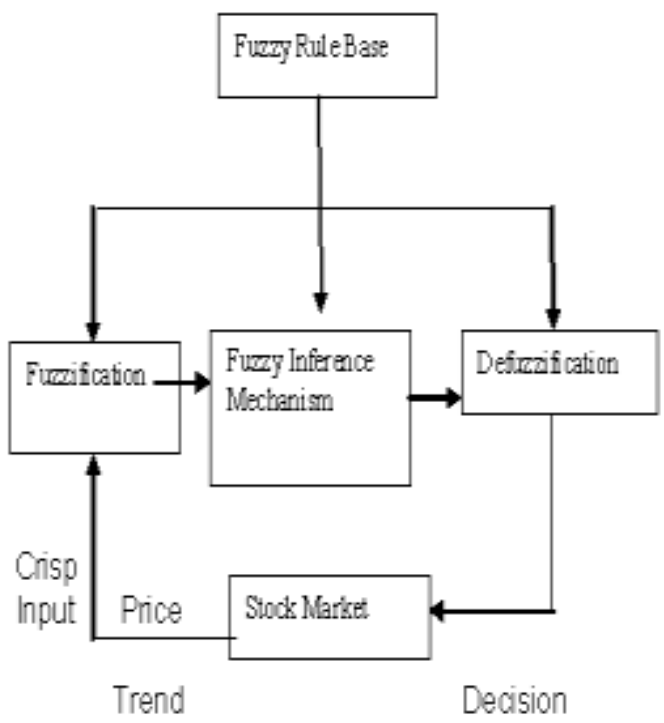

Fig? Fuzzy controller

The fuzzy output set concerning the trading decision (buy, hold, sell) is converted to a crisp decision by applying standard centreof-gravity defuzzyfication. The direction and the amount of the trading are fully determined through the defuzzyficated output.

We take two inputs and one output

Input1: Market growth $=\{$ negative, none, positive $\}$;

Input2: Share Price $=\{$ Low, Medium, High $\}$

Output: Decision $=\{$ Buy, Hold, Sell $\}$

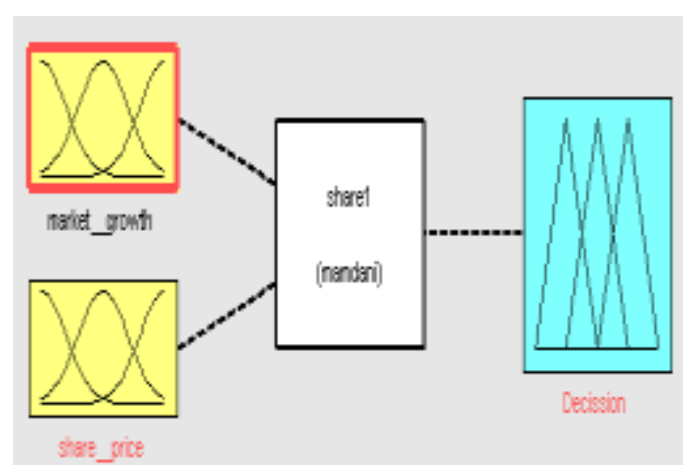

Fig3: Inputs and out puts of FIS editor for mamdani fuzzy controllar

Fuzzy Rules: Some Impartent rules are as follows:

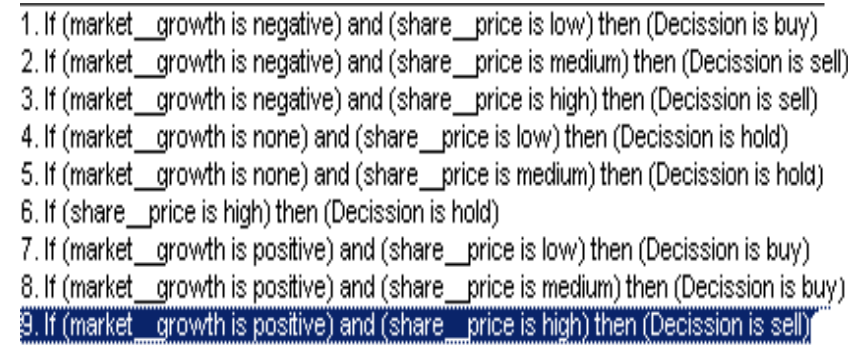

\section{SURFACE VIEW}

Surface view for share market with market growth and share price with the use of MATLAB tool is shown in fig.4.

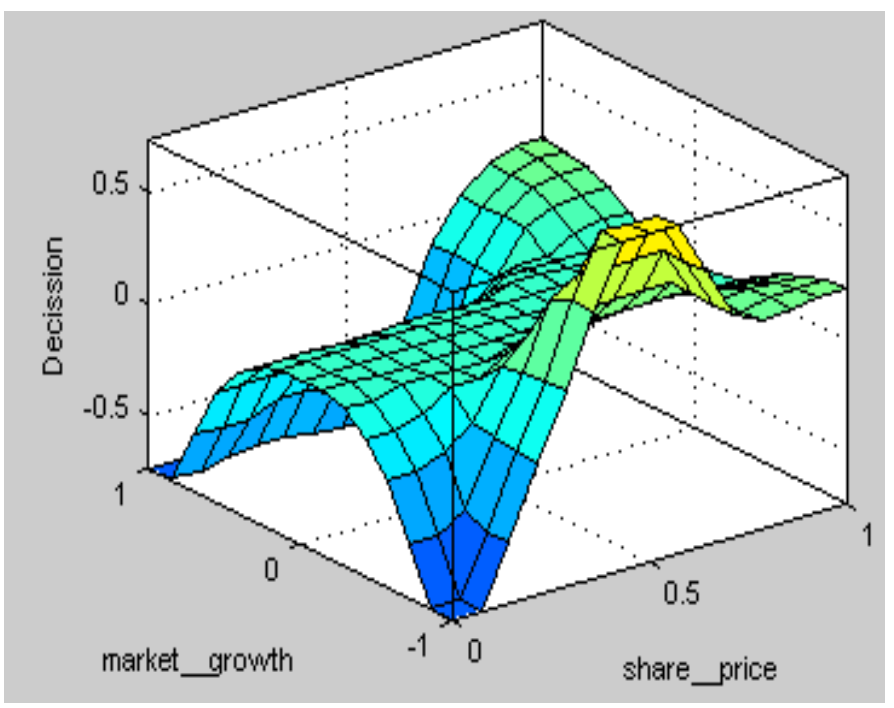

Fig.4: Surface view for share market with market growth and share price

\section{FUZZY METAGRAPH}

Fuzzy Metagraph for share market is shown in fig. 5. This figure shows the three different stages of share market: Buy, Hold and Sell. Fuzzy rules would be applied to obtain certain decisions on particular situation of market growth and share price. The rules are as follows:

If market growth is negative and share price is high then decision is sell. 


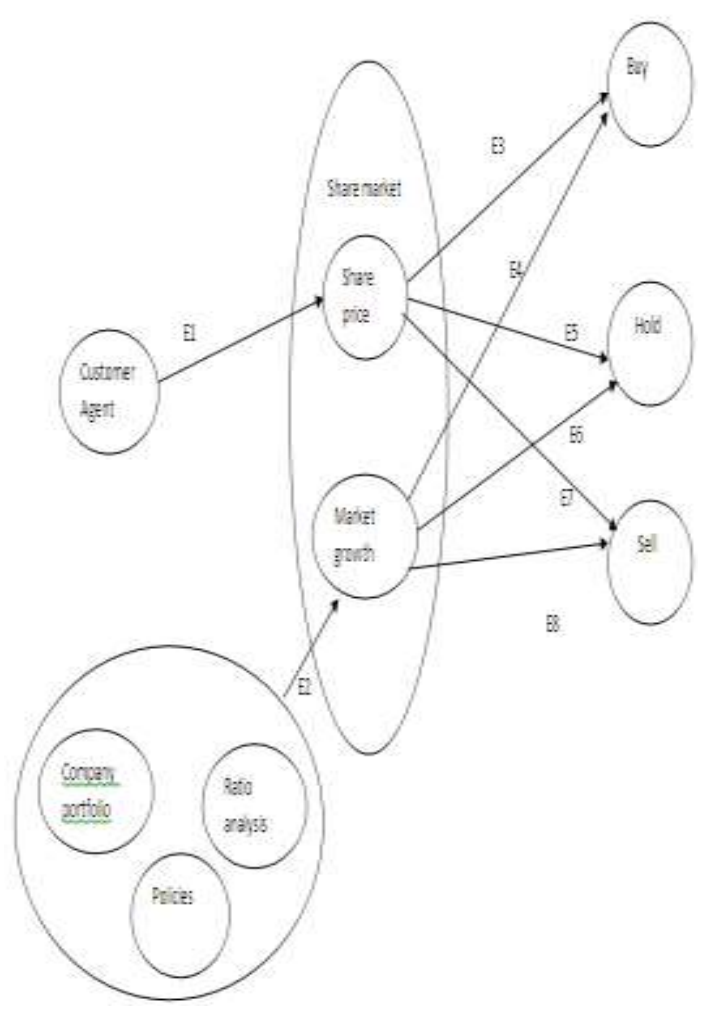

Fig.5:fuzzy Metagraph for share market.

Fig.5 show the fuzzy metagraph for share market where $\mathrm{E} 1, \mathrm{E} 2, \mathrm{E} 3, \mathrm{E} 4, \mathrm{E} 5, \mathrm{E} 6, \mathrm{E} 7, \mathrm{E} 8$ shows the different edges with following description :

E1 : Customer / Agent request

E2 : Company portfolio, policies and Ratio analysis to market growth.

E3 \&E4: Share price and Market growth to Buy the share.

E5\&E6 : Share price and Market growth to Hold the share.

E7\&E8 : Share price and Market growth to Sell the share.

Fuzzy metagraph shows the process of share market the key functions are market growth and share price. Market growth of any share is based on company portfolio and policies of company with their ratio analysis.

\section{RULE VIEWER:}

Fuzzy rule viewer with the help of MATLAB tools is shown in fig. 6 .

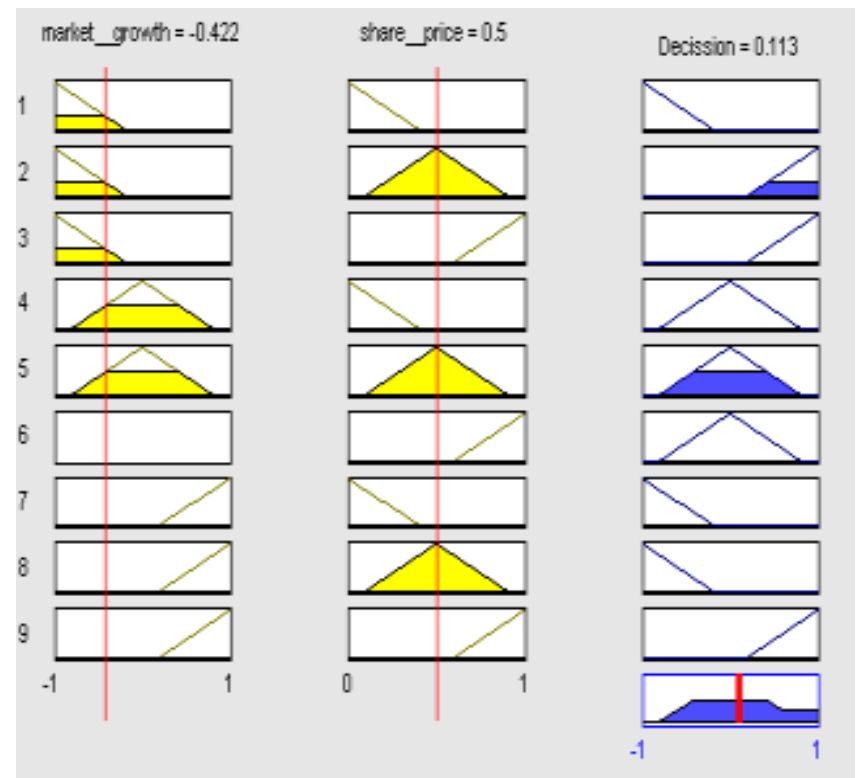

Fig.6: fuzzy rule viewer

\section{RESULTS}

Results of fuzzy control system is shown in Table1.

Table 1: Results of fuzzy controller

\begin{tabular}{|c|c|c|c|}
\hline \multicolumn{2}{|c|}{ Fuzzy Input } & \multirow[t]{2}{*}{ Fuzzy Output } & \multirow[t]{2}{*}{ Decision } \\
\hline Market growth & Share price & & \\
\hline-0.22 & 0.5 & +0.00671 & sell \\
\hline-0.495 & 0.5 & +0.173 & sell \\
\hline-0.917 & 0.5 & +0.737 & sell \\
\hline+0.275 & 0.5 & -0.0283 & buy \\
\hline+0.697 & 0.5 & -0.453 & buy \\
\hline+0.936 & 0.5 & -0.738 & buy \\
\hline-0.881 & 0.205 & -0.18 & buy \\
\hline-0.697 & 0.205 & -0.159 & buy \\
\hline-0.44 & 0.205 & -0.0182 & buy \\
\hline+0.385 & 0.205 & -0.0906 & buy \\
\hline+0.569 & 0.205 & -0.252 & buy \\
\hline+0.771 & 0.205 & -0.586 & buy \\
\hline+0.991 & 0.205 & -0.692 & buy \\
\hline+0.991 & 0.814 & +0.124 & sell \\
\hline+0.587 & 0.814 & +0.109 & sell \\
\hline+0.165 & 0.814 & 0 & hold \\
\hline+0.642 & 0.814 & +0.124 & sell \\
\hline-0.385 & 0.814 & +0.086 & sell \\
\hline-0.679 & 0.814 & +0.2 & sell \\
\hline-0.991 & 0.814 & +0.2 & sell \\
\hline+0.954 & 0.959 & +0.223 & sell \\
\hline+0.22 & 0.959 & +0.00627 & sell \\
\hline-0.239 & 0.959 & +0.0123 & sell \\
\hline-0.589 & 0.959 & +0.154 & sell \\
\hline-0.954 & 0.959 & +0.223 & sell \\
\hline
\end{tabular}




\section{SIMULATION RESULTS}

Simulation graph for share market is shown in fig.

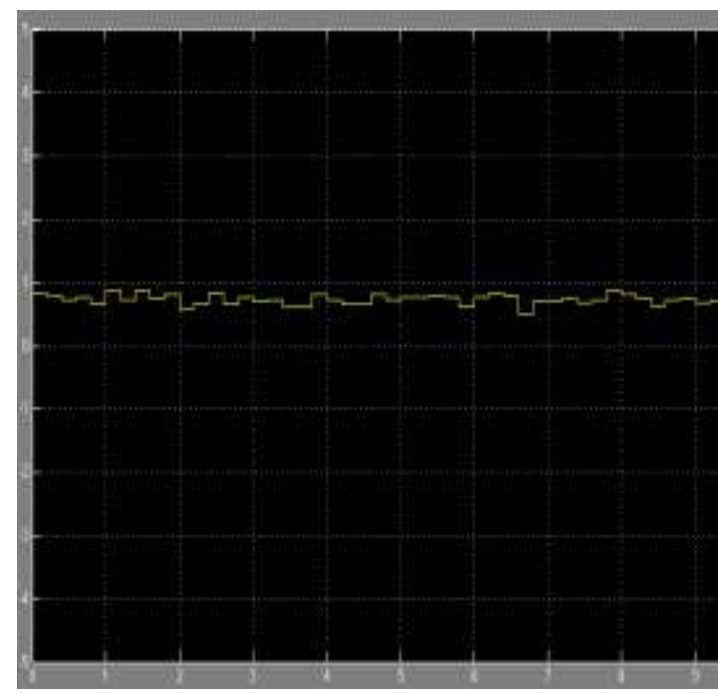

Fig. 7 simulation graph

\section{CONCLUSION}

This research work will help the customer for decision making in share market. Furthermore, based on fuzzy rule based system stock exchange data could be used to overcome uncertainty, vagueness and imprecision of share market. Technical and fundamental approaches are used in parallel to estimate shortterm and long-term return and risk. The customer will more secure to take risk at time of share trading.
The computational results show the portfolio rebalancing model with a appropriate membership function according to the investor's degree of satisfaction. Fuzzy metagraph shows the process of share market. This work help for decision making for a customer to BUY, SELL or HOLD the share at particular situation of market growth.

\section{REFERENCES}

[1] Zadeh L.A., "Knowledge Representation in Fuzzy Logic," IEEE Trans. Knowledge and Data Eng., vol. 1, pp. 89100,1989 .

[2] Dashore P., "Uncertainty Knowledge Representation Through Fuzzy Metagraph" International Journal of computer Application (IJCA), vol 2, pp149-154, 2007.

[3] Basle Committee on Banking Supervision Basle, "Risk Management for Electronic Banking and Electronic Money Activities, March 1998.

[4] Nabil D. Parsiani Shull "Project Evaluation Using Fuzzy Logic and Risk Analysis Techniques”, 2006.

[5] Chandwani M. and Chaudhari N.S., "Knowledge Representation Using Fuzzy Deduction Graphs," IEEE Trans. Systems, Man, and Cybernetics, vol. 26, pp 848854, 1996

[6] Dashore pankaj and Jain Suresh"Fuzzy Rule Based System and Metagraph for Risk Management in Electronic Banking”, IJET,pp97-101 april2009.

[7] www.appuonline.com

[8] BSE and NSE Data.

[9] Basu A. and Blanning R.W., "Metagraphs," Omega, Int'l J. Management Science, vol. 23,pp.13-25,1995. 